\title{
POLYPHENOLS IN CHINESE KUSHUI ROSE (ROSA SERTATA × ROSA RUGOSA) LEAVES
}

\author{
H. XU ${ }^{a, b \S}, Y . W_{A N G}{ }^{a \S}$, F. YUAN ${ }^{a}$ and Y. GAO ${ }^{a *}$ \\ ${ }^{a}$ Beijing Advanced Innovation Center for Food Nutrition and Human Health, Beijing Laboratory for Food \\ Quality and Safety, Beijing Key Laboratory of Functional Food from Plant Resources, College of Food Science \\ and Nutritional Engineering, China Agricultural University, P. O. Box 112, No.17 Qinghua East Road, Haidian \\ District, Beijing, 100083, P.R. China \\ ${ }^{b}$ Beijing Institute of Nutritional Resources, No. 4 Dong Binhe Road, Fengtai District, Beijing, 100069, P.R. China
}

(Received: 27 December 2017; accepted 27 April 2018)

Polyphenols in Chinese Kushui rose (Rosa sertata $\times$ Rosa rugosa) leaves were first extracted and analysed in this study. Among four fractions (ethyl ether, ethyl acetate, $n$-butanol, and water layer) of crude extracts, the ethyl acetate fraction showed the highest $\mathrm{ABTS}^{\bullet+}$ scavenging activity, and the $n$-butanol fraction exhibited the maximum components in composition. On-line HPLC-ABTS ${ }^{\cdot+}$ analysis indicated that there were more than 30 antioxidant compounds from Chinese Kushui rose leaves. The identified polyphenols could be classified into quercetin derivatives, gallic acid derivatives, and proanthocyanidins. Gallic acid was the most antioxidative compound.

Keywords: Chinese Kushui rose leaves, polyphenols, ABTS $^{\bullet+}$ scavenging activity, HPLC-DAD-MS/MS

Roses and their products (essential oils, petals, and extracts) are widely used in food, cosmetic, household cleaning, and medical industries. Rose petals are used as raw materials for products of tea, wine, juice, and jams. Petals and roots of roses have also been utilized in traditional medicine for the treatment of diarrhoea, injuries, gastroenteritis, hepatitis, dysmenorrhea, and blood circulation disorders, as well as pain management and haemostasis maintenance (OCHIR et al., 2010). The extract from rose petals showed excellent reducing capacity and free radical scavenging activity (GE \& MA, 2013), the main antioxidant components of rose petals were gallic acid derivatives ( $\mathrm{NG}_{\mathrm{A}}$ et al., 2004).

Most of reports on rose products were from the species of Rosa sericea, Rosa rugosa, and Rosa damascena Mill. Chinese Kushui rose (Rosa sertata $\times$ Rosa rugosa), mainly planted in Gansu Province of the People's Republic of China, is very famous for its aromatic profile and high content $(\geq 40 \%)$ of citronellol in its essential oil (ZHANG et al., 2003). As various tissues of a plant should have similar phytochemical composition, it implies that Chinese Kushui rose leaves should be good sources of flavonoids. The purpose of the current study was to analyse total phenol contents in the extract of Chinese Kushui rose leaves, and evaluate its active components by on-line HPLC-ABTS ${ }^{\cdot+}$ assay and HPLC-DAD-MS/MS method.

\footnotetext{
* To whom correspondence should be addressed.

Phone: +86 106273 7034; fax:+86106273 7986; e-mail: gyxcau@126.com

$\S$ : These two authors contributed equally to this paper.
} 


\section{Materials and methods}

\subsection{Plant material and chemicals}

The dried Chinese Kushui rose (Rosa sertata $\times$ Rosa rugosa) leaves (moisture, 5.8 $\pm 0.5 \%$ ) were kindly supplied by Gansu Oriental Tianrun Rose Industry Co. Ltd. (Lanzhou, China).

6-Hydroxy-2,5,7,8-tetramethylchroman-2-carboxylic acid (Trolox), Folin-Ciocalteu's reagent (2N), 2,2'-azinobis (3-ethylbenzothiazoline-6-sulfonic acid) diammonium salt (ABTS), (+)-catechin hydrate, and rutin were purchased from Sigma-Aldrich (Shanghai, China).

\subsection{Preparation of the crude extracts and fractions}

The rose leaves powder $(1 \mathrm{~g}, \mathrm{~d}<0.85 \mathrm{~mm})$ was extracted with $30 \mathrm{ml}$ ethanol $(50 \%$, v/v) for $120 \mathrm{~min}(2 \times 60 \mathrm{~min})$ at $70{ }^{\circ} \mathrm{C}$ in a shaking bath (Model DSHZ-300, Suzhou, China). The extracts were then filtered and centrifuged at $2000 \times g$ for $10 \mathrm{~min}$, then the supernatant was evaporated at $50{ }^{\circ} \mathrm{C}$ and $-0.08 \mathrm{MPa}$ to make the soluble solid content up to $8 \%$. The concentrates were further fractionized into four portions by ethyl ether, ethyl acetate, $n$-butanol, and water. Each of the four corresponding fractions was evaporated to dryness at $50{ }^{\circ} \mathrm{C}$ and $-0.08 \mathrm{MPa}$, and then dissolved in methanol and stored at $-18{ }^{\circ} \mathrm{C}$ until used.

\subsection{Determination of total phenolic content (TPC)}

The TPC was measured using aluminium chloride colorimetric assay, following the method described by GoNG and co-workers (2012), and expressed in rutin equivalent.

\subsection{Evaluation of radical scavenging capacity}

The $\mathrm{ABTS}^{-+}$scavenging capacity of Chinese Kushui rose leaves extracts was determined with the procedure described by GoNG and co-workers (2012) and expressed in Trolox equivalent.

On-line HPLC-ABTS ${ }^{*}$ detection was following the method of HE and co-workers (2012) with a slight modification. The differences were in the mobile phase $(2 \%(\mathrm{v} / \mathrm{v})$ formic acid (solvent A) and acetonitrile (solvent B)) and its gradient elution. The solvent A was set from $100 \%$ to $90 \%$ from 0 to $15 \mathrm{~min}$, and kept at $90 \%$ till $20 \mathrm{~min}$, decreased to $85 \%$ at 30 min, then kept at $85 \%$ till $40 \mathrm{~min}$, decreased to $80 \%$ at $50 \mathrm{~min}$, kept at $80 \%$ till $55 \mathrm{~min}$, and decreased to $70 \%$ at $60 \mathrm{~min}$.

\subsection{Identification of polyphenols}

The identification of polyphenols was carried out by comparing the characteristics of DAD spectra, retention time of standard compounds, and MS data to those reported in the literature. The mass detector of the HPLC-MS system was a G6310 ion-trap mass spectrometer (Agilent Technologies Inc., Santa Clara, USA) equipped with an electrospray ionization (ESI) system and controlled by Agilent LC/MSD trap software. Nitrogen was used as nebulizing gas at a pressure of $30 \mathrm{psi}$ with a flow rate of $9.01 \mathrm{~min}^{-1}$. The nebulizer temperature was $325^{\circ} \mathrm{C}$ and capillary voltage was maintained at $4000 \mathrm{~V}$. The compounds were measured at the scan range of the mass spectra from m/z $100 \mathrm{u}$ to m/z $1500 \mathrm{u}$. MS was operated in both positive and negative ion modes. 


\subsection{Statistical analysis}

The whole experiment and all analyses were carried out in triplicate. The data were subjected to analysis of variance (ANOVA) using the Origin Pro 9.0 software (Originlab Corporation, Northampton, USA). Significant differences $(\mathrm{P}<0.05)$ of means were determined by the Tukey's test.

\section{Results and discussion}

\subsection{ABTS $^{++}$scavenging activity of the extracts from Chinese Kushui rose leaves}

Table 1 shows four fractions of the crude extract from Chinese Kushui rose leaves. TPC of ethyl acetate layer (39\%) was the highest, followed by $n$-butanol layer $(37 \%)$, ethyl ether layer $(16 \%)$, and water layer $(8 \%)$. The reason for that could be the different compositions and polarities of their components (GoNG et al., 2012; He et al., 2012). The Trolox equivalent $\mathrm{ABTS}^{\cdot+}$ scavenging capacity and TPC values of the extracts could be at linear correlations $\left(\mathrm{R}^{2}=0.925\right)$ (He et al., 2012).

Table 1. Total phenolic content (TPC) and $\mathrm{ABTS}^{\bullet+}$ scavenging capacities of different fractions of the extract from Chinese Kushui rose leaves

\begin{tabular}{lcc}
\hline Fractions & TPC $(\mathrm{mg} \mathrm{RE} / \mathrm{g})$ & $\mathrm{ABTS}^{\bullet+}(\mathrm{mmol} \mathrm{TE} / \mathrm{g})$ \\
\hline Crude extract & $74.12 \pm 1.26$ & $1.23 \pm 0.12^{\mathrm{d}}$ \\
Ethyl ether layer $(\mathrm{Fa})$ & $12.73 \pm 0.17$ & $0.26 \pm 0.01^{\mathrm{b}}$ \\
Ethyl acetate layer $(\mathrm{Fb})$ & $29.64 \pm 0.83$ & $0.48 \pm 0.01^{\mathrm{c}}$ \\
$n$-Butanol layer $(\mathrm{Fc})$ & $29.85 \pm 0.94$ & $0.51 \pm 0.02^{\mathrm{c}}$ \\
Water layer $(\mathrm{Fd})$ & $6.12 \pm 0.02$ & $0.09 \pm 0.01^{\mathrm{a}}$ \\
\hline
\end{tabular}

RE: rutin equivalent; TE: Trolox equivalent

Values are expressed as means \pm S.D. $(n=3)$; the numbers in each column marked with different superscript letters were significantly $(\mathrm{P}<0.05)$ different.

The HPLC profiles of components and $\mathrm{ABTS}^{\cdot+}$ scavenging antioxidants in the four fractions of the extract are significantly different (Fig. 1). To compare the free radical scavenging capacity of each component, negative absorbance lower than $-100 \mathrm{mAU}$ was chosen as a standard in comparison. It must be noted that ABTS radical scavenging property is only an additional physico-chemical characteristic of polyphenols. On-line HPLC-ABTS ${ }^{*+}$ analysis is used to support the identification of polyphenols and screen them quickly. The intensity of this property cannot be directly associated with better in vivo bioefficacy of identified polyphenols.

In ethyl ether fraction (Fraction A, Fa), compound 1 exhibited higher $\mathrm{ABTS}^{\cdot+}$ scavenging activity. In ethyl acetate fraction (Fb), compounds $1,4,15$ had higher $\mathrm{ABTS}^{\cdot+}$ scavenging capacity. In $n$-butanol fraction (Fc), compounds 1, 11, 14, 15, 20, 22, 25 showed higher $\mathrm{ABTS}^{{ }^{+}}$scavenging activity. In water fraction (Fd), compounds 1 and 26 exhibited higher antioxidant activity. Interestingly, compound 4 was the main radical scavenger in $\mathrm{Fb}$, but not the main scavenger in Fa. This could be ascribed to the different concentrations of compound 4 in $\mathrm{Fa}$ and $\mathrm{Fb}$. Compound 1 was the most significant contributor in all four fractions. 

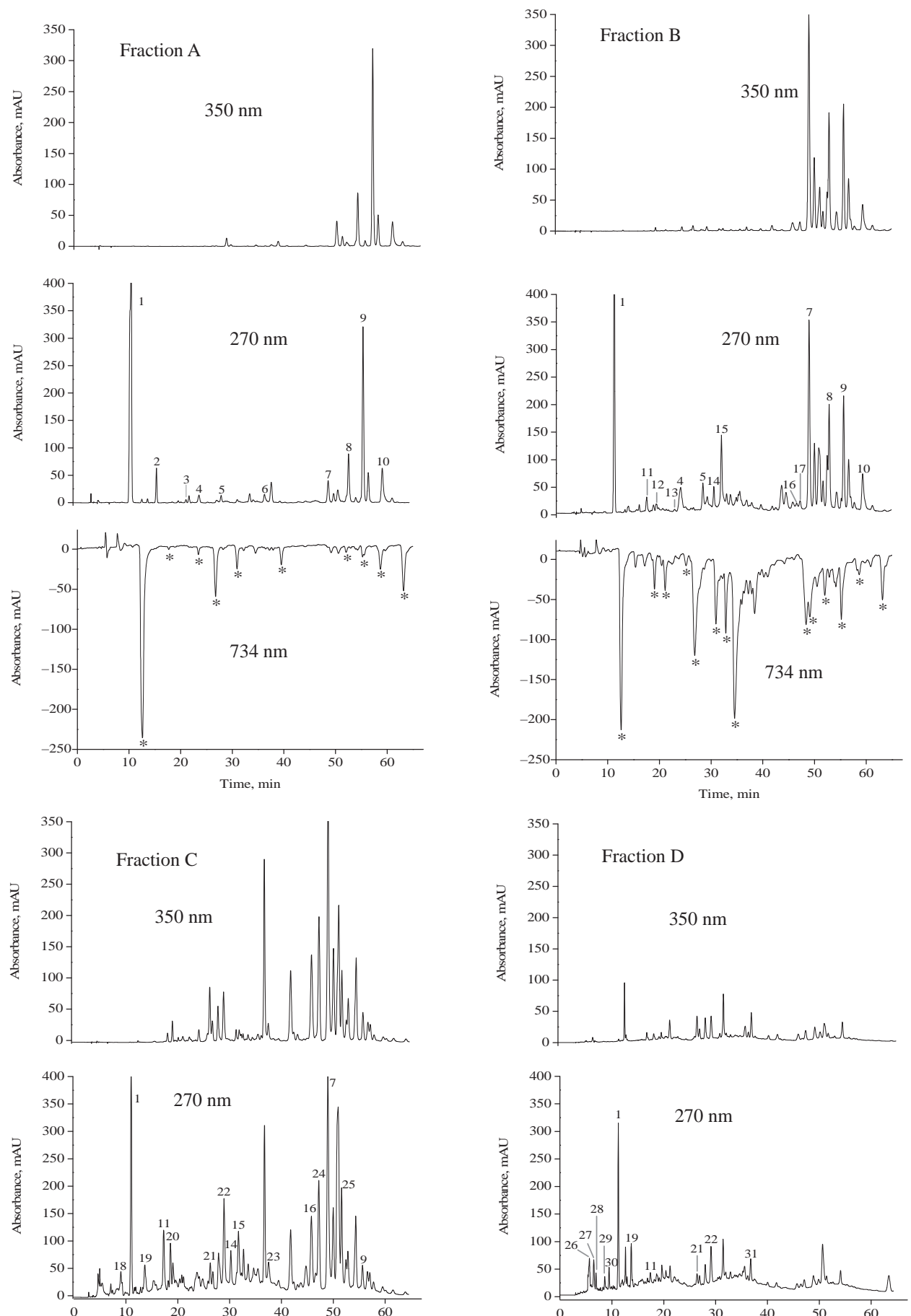

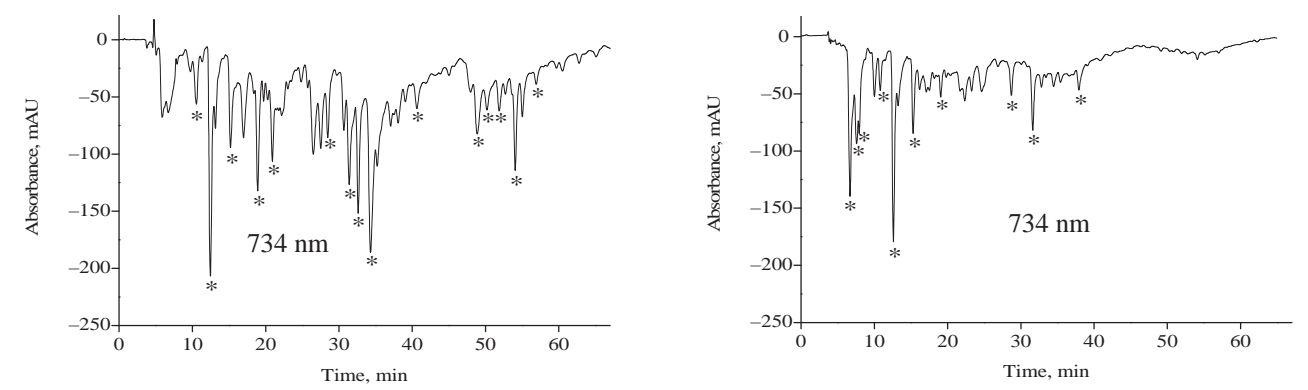

Fig. 1. HPLC chromatograms of Chinese Kushui rose leaves extract (Fraction A: ethyl ether layer fraction; Fraction B: ethyl acetate layer fraction; Fraction C: n-butanol layer fraction; Fraction D: water layer fraction; Absorbance at 270, 350, and $734 \mathrm{~nm}$ were detected for gallic acid derivatives, flavonoids, and $\mathrm{ABTS}^{\bullet+}$ scavenging $^{-}$ compounds; Peak numbers refer to those in Table 2.)

\subsection{Identification of polyphenols in the extract from Chinese Kushui rose leaves}

The chromatographic HPLC-ESI/MS and UV data for the identification of major free radical scavengers, showed in Figure 1, are shown in Table 2.

2.2.1. Quercetin derivatives. The presence of quercetin-3-rutinoside (rutin, 16, 17, 31) was revealed in the extract from Chinese Kushui rose leaves. The ESI-MS spectrum displayed an intense parent ion at $\mathrm{m} / \mathrm{z} 609$, a fragment at $\mathrm{m} / \mathrm{z} 301$ matched with quercetins derivatives. The fragment at $\mathrm{m} / \mathrm{z} 463$ was due to a loss of rhamnose moiety from the parent ion. Moreover, by comparison with the UV-Vis spectra data reported in the literature and retention time of the standard compound, compounds 16,17 , and 24 were identified as epimers of quercetinrhamnosylgalactoside (TiBERTI et al., 2007; He et al., 2010).

Compounds 7 and 31 gave a $[\mathrm{M}-\mathrm{H}]^{-}$ion at $\mathrm{m} / \mathrm{z} 463$, and their $\lambda_{\max }$ was about at $356 \mathrm{~nm}$. Furthermore, the deprotonated molecular ion $[\mathrm{M}-\mathrm{H}]^{-}$yielded a fragment at $\mathrm{m} / \mathrm{z} 301$ on $\mathrm{MS}^{2}$ spectra, therefore, they could be identified as isomers of quercetin hexoside (SEERAm et al., 2006; KAJDŽANOSKA et al., 2010).

Two compounds $(8,9)$ in the ether fraction were detected with $\mathrm{m} / \mathrm{z} 433$ in the MS ${ }^{1}$ analysis, and a fragment at $\mathrm{m} / \mathrm{z} 301$ was detected in the $\mathrm{MS}^{2}$ analysis. According to the DAD spectra data $\left(\lambda_{\max }=354 \mathrm{~nm}\right)$, the fragmentations of both constituents were well in accordance with quercetin pentoside (САROCHO et al., 2014).

Compound 10 gave a $[\mathrm{M}-\mathrm{H}]^{-}$ion at $\mathrm{m} / \mathrm{z} 585$, and its $\lambda_{\max }$ was about at $360 \mathrm{~nm}$. Furthermore, the deprotonated molecular ion $[\mathrm{M}-\mathrm{H}]^{-}$yielded fragments at $\mathrm{m} / \mathrm{z} 301$ and 433 on $\mathrm{MS}^{2}$ spectra. It could be identified as quercetin-O-(O-galloyl)-pentoside (SALDANHA et al., 2013).

Compound 22 was assigned to quercetin-dihexoside according to its pseudomolecular ion $\left([\mathrm{M}-\mathrm{H}]^{-}\right.$at $\left.\mathrm{m} / \mathrm{z} 625\right)$ and fragmentation ions at $\mathrm{m} / \mathrm{z} 463[\mathrm{M}-162-\mathrm{H}]^{-}$and $301[\mathrm{M}-162-$ $162-\mathrm{H}]^{-}$. Such fragmentation pattern and its UV spectrum $\left(\lambda_{\max }=352 \mathrm{~nm}\right)$ confirmed the presence of quercetin-dihexoside (WiLLIAM et al., 2003).

Compound 23 was identified as an O-glycoside of quercetin according to the UV spectrum $\left(\lambda_{\max }=256,364 \mathrm{~nm}\right)$ and a major $\mathrm{MS}^{2}$ ion at $\mathrm{m} / \mathrm{z} 300(\mathrm{M}-\mathrm{H}-448)$. This analysis also showed that compound 23 contained one additional deoxyhexose sugar unit $\left(\mathrm{MS}^{2}\right.$ ion at $\mathrm{m} / \mathrm{z}$ 591 [M-H-164] $]^{-}$. The loss of the deoxyhexose residue (146 amu for deoxyhexose) yielded a $\mathrm{MS}^{2}$ ion at m/z 609 (Simirgiotis et al., 2009). 


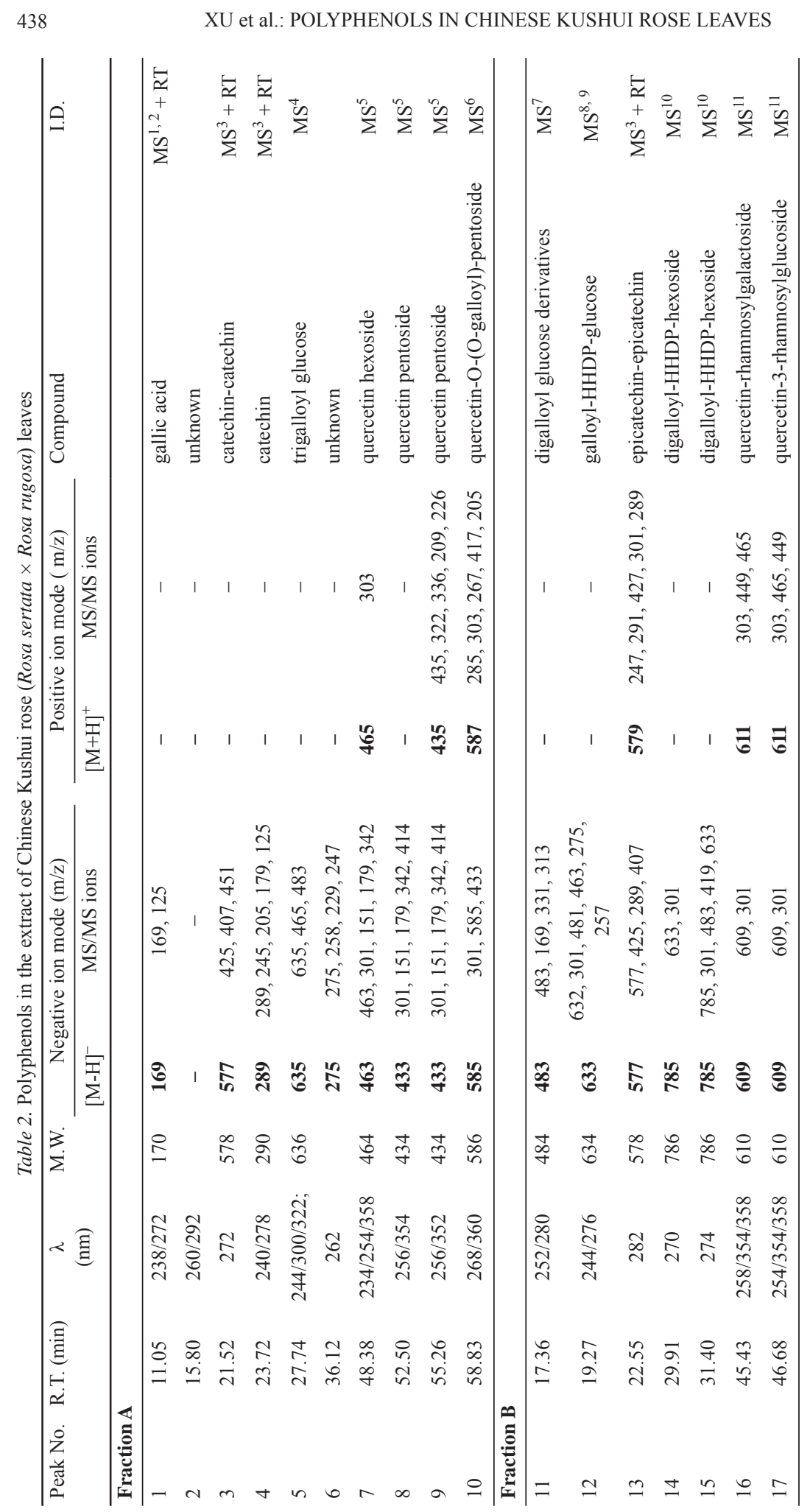

Acta Alimentaria 47, 2018 
XU et al.: POLYPHENOLS IN CHINESE KUSHUI ROSE LEAVES

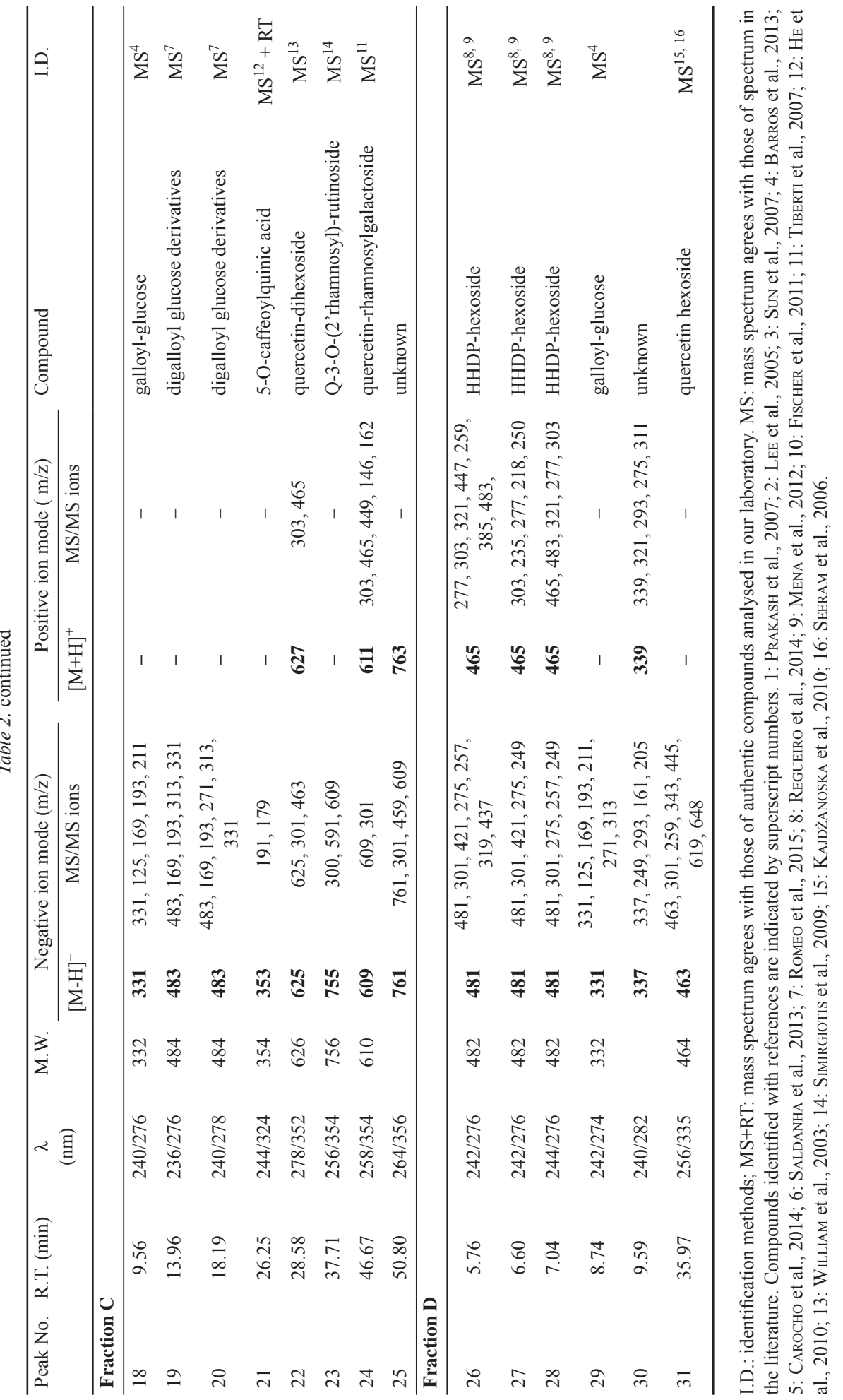


2.2.2. Gallic acid derivatives. The aglycone of ellagic acid showed the same $[\mathrm{M}-\mathrm{H}]^{-}$ion at $\mathrm{m} / \mathrm{z} 301$ like quercetin. However, ellagic acid produced fragments at $\mathrm{m} / \mathrm{z} 258,229$ and 185 in the $\mathrm{MS}^{2}$ analysis, whereas quercetin generated fragments at $\mathrm{m} / \mathrm{z} 179$ and 151 (Romeo et al., $2015)$. Furthermore, both compounds significantly differed in their UV-Vis spectra $\left(\lambda_{\max }\right.$; ellagic acid: 275 and $367 \mathrm{~nm}$; quercetin: 252, 286, and $372 \mathrm{~nm}$ ), thus allowing them differentiated unambiguously.

Compounds 11, 19, 20 gave the same $[\mathrm{M}-\mathrm{H}]^{-}$ion at $\mathrm{m} / \mathrm{z} 483$ in accordance with a molecular formula $\mathrm{C}_{20} \mathrm{H}_{20} \mathrm{O}_{14}$. Their $\lambda_{\text {max }}$ were about $276 \mathrm{~nm}$. Their deprotonated molecular ions $[\mathrm{M}-\mathrm{H}]^{-}$yielded four fragments at $\mathrm{m} / \mathrm{z} 331,313,193$, and 169 on $\mathrm{MS}^{2}$ spectra, which represented different diagnostic fragmentations of galloyl, glucose, digalloyl, and gallic acid, respectively. Moreover, the relative intensities of ions in each spectrum were significantly different at the same $\mathrm{MS}^{2}$ condition. In this study, there were some conspicuous fragmentation differences amongst the three compounds. The fragmentation behaviours of both constituents were in accordance with those detected by MEYERS and co-workers (2006). Identification of compounds 11, 19, 20 was achieved by comparing their ESI-MS ${ }^{2}$ spectra and they could be identified as digalloyl glucose derivatives. Compound 5 was identified as trigalloyl glucose, and compounds 18 and 29 were identified as galloyl-glucose (BARRos et al., 2013).

In water fraction, compounds $12,26,27$, and 28 were detected with $\mathrm{m} / \mathrm{z} 481$ in the $\mathrm{MS}^{1}$ analysis. All these compounds produced a fragment at $\mathrm{m} / \mathrm{z} 301$, and their $\lambda_{\max }$ were about at $275 \mathrm{~nm}$, which indicated an ellagic acid moiety released. Three compounds were tentatively identified as hexahydroxydiphenoyl-hexoside (HHDP-hexoside) (Mena et al., 2012; RegueIro et al., 2014).

Compounds 14 and 15 were characterized as digalloyl-HHDP-hexoside (pedunculagin II). The DAD spectra data and fragmentation behaviours of both compounds were in accordance with literature data (FISCHER et al., 2011). Their [M-H] ${ }^{-}$ion were at $\mathrm{m} / \mathrm{z} 785$ and typical ellagitannin and gallotannin fragments were released at $\mathrm{m} / \mathrm{z} 483$ (digalloyl-hexoside), 301 (ellagic acid), and 633 (galloyl-HHDP-hexoside). Their different retention times were ascribed to their isomeric structures resulting in their different fragmentation patterns.

Compound 1, the most abundant and effective antioxidative component, gave a negative ion at $\mathrm{m} / \mathrm{z} 169[\mathrm{M}-\mathrm{H}]^{-}$and fragment ion at $\mathrm{m} / \mathrm{z} 125\left[\mathrm{M}-\mathrm{CO}_{2}\right]^{+}$, the compound could be recognized as gallic acid by comparison with the published data (LeE et al., 2005; PraKASH et al., 2007).

2.2.3. Proanthocyanidins. The mass spectra showed the deprotonated molecule $[\mathrm{M}-\mathrm{H}]$ of catechin at $\mathrm{m} / \mathrm{z} 289$ with the characteristic $\mathrm{MS}^{2}$ ions at $\mathrm{m} / \mathrm{z} 245,205,179,125$, and UV maximum at $280 \mathrm{~nm}$. For epicatechin, its mass spectra were same to those of catechin, but the $\lambda_{\text {max }}$ of epicatechin was $270 \mathrm{~nm}$ (Dincheva et al., 2013).

Compounds 3 and 13 had $[\mathrm{M}-\mathrm{H}]^{-}$at $\mathrm{m} / \mathrm{z} 577$ and main fragmentation with a loss of 152 amu were recognized as proanthocyanidin dimmers (Sun et al., 2007). On considering the $\lambda_{\max }$ of catechin and epicatechin, Compound 3 was recognized as the dimer of catechincatechin, compound 13 was recognized as the dimer of epicatechin-epicatechin, and compound 4 was recognized as catechin.

2.2.4. Miscellaneous. Compound 21 generated a $[\mathrm{M}-\mathrm{H}]^{-}$ion at $\mathrm{m} / \mathrm{z} 353$, and two fragment ions at m/z 191 and 179. Based on its $\lambda_{\max }$ at $325 \mathrm{~nm}$ and the retention time of authentic compound, compound 21 was identified as 5-O-caffeoylquinic acid (HE et al., 2010). 


\section{Conclusions}

In conclusion, $50 \%$ ethanol solution was an effective solvent to obtain crude extract from Chinese Kushui rose leaves. Although the in vitro $\mathrm{ABTS}^{\cdot+}$ scavenging capacity of a compound is not equivalent to its in vivo physiological action, on-line HPLC-ABTS ${ }^{\cdot+}$ analysis is still helpful in screening bioactive components in herbal extracts. There were 31 main polyphenols contributing to the $\mathrm{ABTS}^{-+}$scavenging activity of the extract from Chinese Kushui rose leaves, and the compound with the most antioxidant capacity was gallic acid.

\section{References}

Barros, L., Dueñas, M., Alves, C.T., Silva, S., Henriques, M., Santos-Buelga, C. \& Ferreira, I.C.F.R. (2013): Antifungal activity and detailed chemical characterization of Cistus ladanifer phenolic extracts. Ind. Crop. Prod., 41, 41-45.

Carocho, M., Barros, L., Bento, A., Santos-Buelga, C., Morales, P. \& Ferreira, I.C.F.R. (2014): Castanea sativa Mill. flowers amongst the most powerful antioxidant matrices: A phytochemical approach in decoctions and infusions. BioMed Res. Int. http://dx.doi.org/10.1155/2014/232956.

Dincheva, I., Badjkov, I., Kondakova, V., Dobson, P., McDougall, G. \& Stewart, D. (2013): Identification of the phenolic components in Bulgarian raspberry cultivars by LC-ESI-MS ${ }^{n}$. Int. J. Agric. Sci. Res., 3, 127-138.

Fischer, U.A., Carle, R. \& Kammerer, D.R. (2011): Identification and quantification of phenolic compounds from pomegranate (Punica granatum L.) peel, mesocarp, aril and differently produced juices by HPLC-DAD-ESI/ MS $^{\mathrm{n}}$. Food Chem., 127, 807-821.

GE, Q. \& MA, X. (2013): Composition and antioxidant activity of anthocyanins isolated from Yunnan edible rose (An ning). Food Sci. Human Wellness, 2, 68-74.

Gong, Y., Liu, X., He, W., Xu, H., Yuan, F. \& GAO, Y. (2012): Investigation into the antioxidant activity and chemical composition of alcoholic extracts from defatted marigold (Tagetes erecta L.) residue. Fitoterapia, 83, 481489.

He, L., Zhang, X., Xu, H., Xu, C., Yuan, F., KneZ, Z., Novak, Z. \& GaO, Y. (2012): Subcritical water extraction of phenolic compounds from pomegranate (Punica granatum L.) seed residues and investigation into their antioxidant activities with HPLC-ABTS ${ }^{++}$assay. Food Bioprod. Process, 90, 215-223.

He, W., Liu, X., Xu, H., Gong, Y., Yuan, F. \& GaO, Y. (2010): On-line HPLC-ABTS screening and HPLC-DAD-MS/ MS identification of free radical scavengers in gardenia (Gardenia jasminoides Ellis) fruit extracts. Food Chem., 123, 521-528.

KajdžAnoska, M., GJamovski, V. \& Stefova, M. (2010): HPLC-DAD-ESI-MS ${ }^{\mathrm{n}}$ identification of phenolic compounds in cultivated strawberries from Macedonia. Maced. J. Chem. Chem. Eng., 29, 181-194.

LeE, J., Johnson, J.V. \& TAlcott, S.T. (2005): Identification of ellagic acid conjugates and other polyphenolics in muscadine grapes by HPLC-ESI-MS. J. Agr. Food Chem., 53, 6003-6010.

Mena, P., Calani, L., Dall'Asta, C., Galaverna, G., García-Viguera, C., Bruni, R., Crozier, A. \& Rio, D.D. (2012): Rapid and comprehensive evaluation of (poly)phenolic compounds in pomegranate (Punica granatum L.) juice by UHPLC-MS ${ }^{\mathrm{n}}$. Molecules, $17,14821-14840$.

Meyers, K.J., Swiecki, T.J. \& Mitchell, A.E. (2006): Understanding the native Californian diet: Identification of condensed and hydrolyzable tannins in Tanoak acorns (Lithocarpus densiflorus). J. Agr. Food Chem., 54, 7686-7691.

NG, T.B., He, J.S., Niu, S.M., Zhao, L., Pi, Z.F., Shao, W. \& Liu, F. (2004): A gallic acid derivative and polysaccharides with antioxidative activity from rose (Rosa rugosa) flowers. J. Pharm. Pharmacol., 56, 537-545.

Ochir, S., Park, B.J., Nishizawa, M., Kanazawa, T., Funaki, M. \& Yamagishi, T. (2010): Simultaneous determination of hydrolysable tannins in the petals of Rosa rugosa and allied plants. J. Nat. Med., 64, 383-387.

Prakash, D., Singh, B.N. \& Upadhyay, G. (2007): Antioxidant and free radical scavenging activities of phenols from onion (Allium cepa). Food Chem., 102, 1389-1393.

Regueiro, J., SÁnchez-González, C., Vallverdú-Queralt, A., Simal-Gándara, J., Lamuela-Raventós, R. \& IzQuierdo-Pulido, M. (2014): Comprehensive identification of walnut polyphenols by liquid chromatography coupled to linear ion trap-Orbitrap mass spectrometry. Food Chem., 152, 340-348. 
Romeo, F.V., Ballistreri, G., Fabroni, S., Pangallo, S., Li Destri Nicosia, M.G., Schena, L. \& Rapisarda, P. (2015): Chemical characterization of different sumac and pomegranate extracts effective against Botrytis cinerea rots. Molecules, 20, 11941-11958.

Saldanha, L.L., Vilegas, W. \& DokKeDAl, A.L. (2013): Characterization of flavonoids and phenolic acids in Myrcia bella Cambess. Using FIA-ESI-IT-MS ${ }^{\mathrm{n}}$ and HPLC-PAD-ESI-IT-MS combined with NMR. Molecules, 18, 8402-8416.

Seeram, N.P., Lee, R., Scheuller, H.S. \& Heber, D. (2006): Identification of phenolic compounds in strawberries by liquid chromatography electrospray ionization mass spectroscopy. Food Chem., 97, 1-11.

Simirgiotis, M.J., Caligari, P.D.S. \& Schmeda-Hirschmann, G. (2009): Identification of phenolic compounds from the fruits of the mountain papaya Vasconcellea pubescens A. DC. grown in Chile by liquid chromatographyUV detection-mass spectrometry. Food Chem., 115, 775-784.

Sun, J., Liang, F., Bin, Y., Li, P. \& Duan, C. (2007): Screening non-colored phenolics in red wines using liquid chromatography/ultraviolet and mass spectrometry/mass spectrometry libraries. Molecules, 12, 679-693.

Tiberti, L.A., Yariwake, J.H., Ndjoko, K. \& Hostettmann, K. (2007): On-line LC/UV/MS analysis of flavonols in the three apple varieties most widely cultivated in Brazil. J. Brazil Chem. Soc. 18, 100-105.

William, M., Yokota, T., Leanc, M.E.J. \& Crozier, A. (2003): Analysis of ellagitannins and conjugates of ellagic acid and quercetin in raspberry fruits by LC-MS ${ }^{\mathrm{n}}$. Phytochemistry, 64, 617-624.

Zhang, R., Wei, A., Yang, T., SA, W. \& Yang, H. (2003): Studies on three kinds of fragrant type rose essential oil properties. Acta Bot. Boreal.-Occident Sin., 23, 1768-1771. (in Chinese) 